\title{
Conformity as a function of experimentally induced minority and majority competence'
}

PHILIP R. COSTANZO, HAROLD T. REITAN, AND MARVIN E. SHAW UNIVERSITY OF FLORIDA

Two levels of minority competence and four levels of majority competence were induced by means of bogus feedback on 10 nonpressure perceptual trials. On the ensuing 15 conformity pressure trials it was found that high competent minority Ss conformed less than low competent Ss, and there was a direct relationship between the conformity behavior of the minority $S s$ and the number of purportedly high competent subjects in the majority.

Deutsch \& Gerard (1955) hypothesized that the more uncertain an individual is about his own judgments the more likely he is to be susceptible to informational social influence. This proposition has been tested in several studies using false feedback to establish individual subject and group or partner competence (Mausner, 1954; Samelson, 1957; Goldberg \& Lubin, 1958; Rosenberg, 1963). Each of these studies showed that the greater the individual's perceived competence relative to the group, the less he tends to conform. In related research Mausner \& Block (1957) and Kelman (1950) found that the greater the prior success of the $S$ in relation to a partner's success, the less his tendency to conform.

In all of these studies, only majorities of uniform competence were used; hence the question of whether conformity increases as a function of the relative number of high-competent members in the majority has not been answered. The present study was designed to answer this question. It was hypothesized that under all conditions of perceived majority competence, a low-competent minority member would conform more than a high-competent minority member. It was also predicted that conformity would vary directly with the number of high-competent members in a simulated majority.

\section{Mefhod}

Ninety-six female undergraduates were randomly assigned to the cells of a 3 by 2 by 4 factorial design, representing three $\mathrm{Es}$, two levels of minority competence (high and low), and four levels of majority competence (high, intermediate high, intermediate low, and low). In addition, 12 Ss were run in each of two control groups: a nonfeedback, pressure (P) control and a nonfeedback, nonpressure (NP) control.

The apparatus used was described by Costanzo \& Shaw (1966) and was similar to that described by Crutchfield (1955). It consisted of a central experimenter cubicle and four subject cubicles. The E cubicle contained master light and switch panels and a Beseler opaque projector. Each $\mathrm{S}$ cubicle contained a panel of 20 lights arranged in four rows of five lights each (one row for each $\mathrm{S}$ and one light for each of five response alternatives). For the purposes of this experiment only the first three columns of lights were used to limit the possible responses to three. Five switches were placed immediately below the fourth row of lights. Each switch activated one light in the fourth row of lights on a given S's panel, and a corresponding light on E'S master panel. Although each $S$ inferred that the first three rows of lights reflected the judgments of the other Ss, the lights were actually controlled by $\mathrm{E}$.

The stimulus materials consisted of 30 cards (10 "practice" and 20 test cards) containing three geometric figures of different sizes. These figures were projected onto a screeen located approximately $10 \mathrm{ft}$ from the $S$ cubicles. The S's task was to judge which of the three figures was largest in area.

The Ss reported to the laboratory in groups of four. The nature of the task was explained and response sheets for the practice trials were distributed. All Ss were requested to note the number of their cubicle which was indicated on their response sheet (all were numbered "4"). Each stimulus was projected on the screen for $3 \mathrm{sec}$, removed, and Ss were then asked to indicate their judgment.

On the first 10 trials Ss indicated their judgments of area on their response sheets. Following the presentation of the tenth stimulus card, the response sheets were collected by $\mathbf{E}$ and he "graded" them and reported the "results" by subject number, according to a predetermined random schedule. Subject 4 was informed that she had been correct on either four (low competence) or eight (high competence) of the 10 trials. The same type of information was reported for Ss 1,2 , and 3 to establish the four levels of majority competence. Indicated competencies of the three majority members were: (1) all high (High); (2) two high and one low (High intermediate); (3) one high and two low (Low intermediate); and (4) all low (Low).

The second set of 20 stimulus cards was presented in the same manner as the initial set; however, Ss were instructed to respond by means of the switches in their cubicles. In all cases "'S 4" responded last. On 15 of the 20 trials the majority judgment was unanimously wrong; i.e., the smallest figure was 


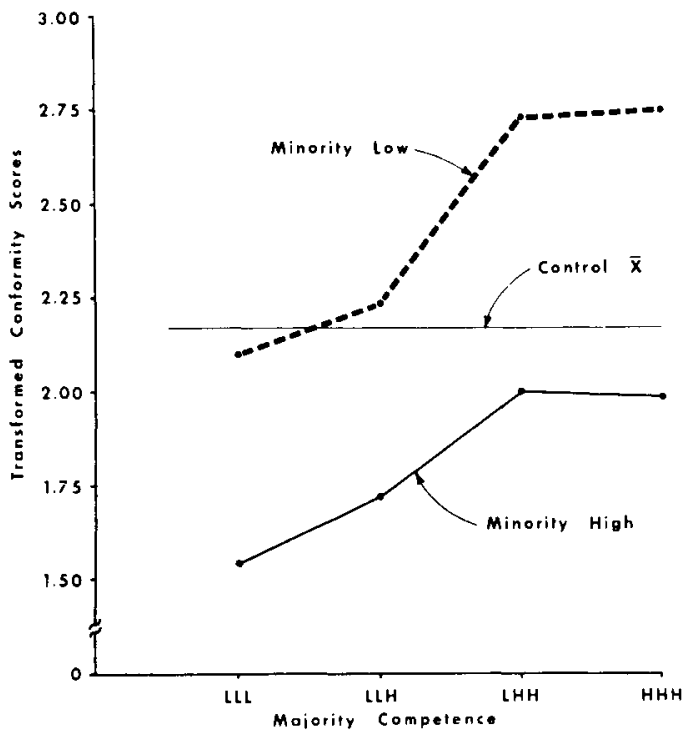

Fig. 1. Conformity at two levels of minority competence as a function of majority competence.

chosen. Agreement with this unanimously wrong majority judgment was defined as conformity behavior. Results

Initially, it should be noted that only two of the 12 NP control Ss selected the smallest figure on one of the 15 critical trials, whereas 96 of the 108 Ss subjected to pressure yielded at least once, and made a total of 430 conforming responses. Also, Ss chose the smallest figure 23 out of 960 times on the initial 10 trials and 378 out of 1440 opportunities on the 15 conformity trials $(p<.001)$.

For the main analysis, the raw conformity score was corrected for each $\mathbf{S}$ by subtracting from it the errors he made on the 10 initial nonpressure trials. Corrected conformity scores were transformed $\left(x^{\prime}=\right.$ $\sqrt{\mathrm{x}+.5)}$ to correct for positive skewness.

Analysis indicated that both the main effects of subject competence $(F=26.38, d f=1 / 72, p<.001)$ and group competnece $(F=5.16, d f=3 / 72, p<.01)$ have significant effects on conformity behavior, as shown in Fig. 1. As predicted, individuals purportedly low in competence conformed more than those high in competence under all conditions of group competence. Furthermore, the greater the number of high-competent individuals in the simulated majority the greater the conformity of the minority $\mathrm{S}$.

Discussion

The results clearly show that the number of high- competent members in a majority increases conformity to the majority judgment. One hypothesis that might explain this result is an ability summation hypothesis. This assumes that the minority member sums the perceived abilities of the majority members to arrive at a single estimate of group competence; conformity is a function of the relation between this estimate of majority competence and the S's estimate of his own competence. However, this hypothesis appears to be inconsistent with Asch's (1951) finding that maximum conformity occurs with a majority of three. Assuming that in Asch's study all Ss were perceived as approximately equal in ability, the summation hypothesis would predict increasing conformity with increasing majority size.

The incompatibility of Asch's results and summation hypothesis predictions suggests an averaging hypothesis which holds that the minority member averages the perceived abilities of the majority in estimating majority competence. Conformity is again viewed as varying as a function of estimated majority competence and the person's estimate of his own competence. Adequate test of this hypothesis requires further experimentation.

Finally, it should be noted that the results from this study are consistent with the Deutsch \& Gerard (1955) hypothesis concerning the effects of informational social influence.

\section{References}

ASCH, S. E. Effects of group pressure on the modification and distortion of judgments. In H. Geutzkow (Ed.), Groups, leadership, and men. Pittsburgh: Carnegie, 1951.

COSTANZO, P. R., \& SHAW, M. E. Conformity as a function of age level. Child Develp., 1966, 37, 967-975.

CRUTCHFIELD, R. S. Conformity and character. Amer. Psychologist, 1955, 10, 191-198.

DEUTSCH, M., \& GERARD, H. B. A study of normative and informational social influence upon individual judgments. J. abnorm. soc. Psychol., 1955, 51, 629-636.

GOLDBERG, S. C., \& LUBIN, A. Influence as a function of perceived judgment error. Hum. Rel., 1958, 11, 175-180.

KELMAN, H. C. Effects of success and failure on "suggestibility" in the autokinetic situation. J. abnorm. soc. Psychol, 1950, 45, 267-285.

MAUSNER, B. The effect of one partner's success in a relevant task on the interaction of observer pairs. J. abnorm. soc. Psychol, $1954,49,557-560$.

MAUSNER, B., \& BLOCH, BARBARA L. A study of the additivity of variables affecting social interaction. J. abnorm. soc. Psychol, $1957,54,250-256$.

ROSENBERG, L. A. Conformity as a function of confidence in self and confidence in partner. Hum. Rel., 1963, 16, 131-139.

SAMELSON, F. Conforming behavior under two conditions of conflict in the cognitive field. J. abnorm. soc. Psychol, 1957, 55, 181-187. Note

1. Grateful acknowledgment is made to Fred Axelberg for serving as an experimenter for this study. 